\title{
Ways to reduce cesarean surgery
}

\section{Modalităţi de reducere a operaţiei cezariene}

\author{
Masoumeh BIRJANDI ${ }^{1,2}$, Dimitrie NANU ${ }^{3}$ \\ ${ }^{1}$ Spitalul Universitar de Urgenţă, Bucureşti, România \\ ${ }^{2}$ Elkhatib Medica SRL, Bucureşti, România \\ 3UMF „Carol Davila“, Bucureşti, România
}

\begin{abstract}
The rate of cesarean section has increased in a very fast way in the last three decades all around the world. In Romania, the rate has dramatically increased after 1990. Romania occupies the third position in Europe with a rate of $37 \%$ of cerean sections from the total number of births.

This paper aim is to illustrate ways for reducing the number of caesarean surgeries in Romania and it is based on both analysis of multiple scientific papers and author's own experience.

Results. We will identify the causes of cesarean surgery that can be avoided in such a way that birth can occur naturally. In general, among the most discussed clinical situations is listed the high-risk pregnancy and the second caesarean section. In order to reduce this worrying cessation rate, more interventions in the current health system are needed: better medical staff training as well as better communication and collaboration between the patient and the doctor in assessing all the risks of doing so operations.

Conclusions. The high percentage of cesarean operations in Romania can be reduced by providing better and quality services to pregnant women.
\end{abstract}

Keywords: cesarean surgery, prevalence, comparative analysis

\section{REZUMAT}

Prevalența operației cezariene a fost alarmantă în ultimele 3 decenii. În România, rata operațiilor cezariene a crescut în mod dramatic după anul 1990. România se află pe locul 3 în Europa, cu un procent de 37\% de operații cezariene din totalul de naşteri.

Scopul acestei lucrări este de a pune în evidență modalități de reducere a numărului de operații cezariene în România. Această lucrare se bazează atât pe o analiză comparativă realizată între diverse alte lucrări ştiințifice, cât şi pe experiența proprie a autorilor.

Rezultate. Se vor identifica cauzele efectuării operațiilor cezariene care pot fi evitate în aşa fel încât naşterea să poată avea loc pe cale naturală. În general, printre cele mai discutate situații clinice se enumeră sarcina cu risc crescut şi a doua cezariană. Pentru a reduce această rată îngrijorătoare a operațiilor cezariene, sunt necesare mai multe intervenții la nivelul sistemului sanitar actual: o pregătire mai bună a personalului medical, dar şi o comunicare şi o colaborare mai bună între pacient şi medic în evaluarea tuturor riscurilor efectuării unei astfel de operații.

Concluzii. Procentul crescut al operațiilor cezariene în România poate fi redus prin asigurarea unor servicii medicale mai bune şi de calitate gravidelor.

Cuvinte cheie: operație cezariană, prevalență, analiză comparativă 


\section{INTRODUCERE}

Naşterea prin operaţie cezariană reprezintă utilizarea unei intervenţii chirurgicale pentru a extrage fătul (unul sau mai mulţi copii) din cavitatea uterină [2]. Operaţia cezariană este cea mai frecventă intervenţie chirurgicală obstetricală efectuată la femei [3].

Printre indicaţiile operaţiei cezariene se enumeră: distocie, patologie cicatricială cervico-vagino-perineală, sarcină asociată cu cancer de col uterin, boli preexistente sarcinii, placenta praevia, abruptio placentae, hipertensiunea arterială asociată sarcinii, sindrom de abdomen acut chirurgical, ruptură uterină, uter cicatriceal, sarcină multiplă, ruperea prematură a membranelor, ruptură precoce de membrane, patologia cordonului ombilical, alte cauze de patologie a anexelor fetale, infecţii materne cu transmitere materno-fetală, suferinţă fetală acută şi cronică şi sarcinile cu izoimunizare în sistemul Rh.

Printre potenţialele riscuri ale operaţiei cezariene se enumeră: creşterea morbidităţii pe termen scurt, creşterea ratelor de apariţie a endometritei, transfuziilor şi trombozelor venoase, creşterea perioadei de internare şi creşterea timpului de convalescenţă, creşterea morbidităţii pe termen lung, creşterea riscului pentru placenta accreta şi histerectomie cu cezarienele următoare.

Rata de naştere a operaţiilor cezariene variază substanţial între naţiuni şi instituţii, dar continuă să crească în întreaga lume [1]. Rata naşterilor prin cezariană întâlnită până în anul 2014 era sub 1015\%, procent care a crescut la 13\% în 2015 [4], conform datelor OMS.
În foarte multe ţări, prevalenţa operaţiei cezariene a fost alarmantă în ultimele 3 decenii [9]. Este foarte bine cunoscut faptul că operaţia cezariană a adus şi multe beneficii în cazul finalizării sarcinilor, însă atât specialiştii, cât şi publicul se întreabă oare cât de mult mai poate fi extins acest procent de operaţii [6].

Multe studii arată că în România s-a înregistrat o creştere progresivă a procentului de operaţii cezariene, de la 11,5\% în 1999 la 37\% în 2016, cu menţiunea că numărul de astfel de operaţii a fost mai mare în cazul pacientelor din zona urbană (fig. 1).

În România, procentul de operaţii cezariene este mai mare în sectorul privat faţă de cel public, cu o prevalenţă de $60 \%$ (cezariană) la $40 \%$ (cale naturală), iar numărul de paciente cu un nivel de educaţie ridicat ce efectuează operaţia cezariană este mai mare decât numărul de paciente cu un nivel de educaţie inferior (fig. 2).

\section{MATERIAL ŞI METODĂ}

Scopul aceste lucrări este de a identifica deferite strategii pentru reducerea procentului de operaţii cezariene, bazandu-se atât pe literatura de specialitate, cât şi pe experienţa proprie a autorilor.

Punctul de start al acestui studiu este de a identifica cauzele efectuării operaţiei cezariene pentru ca, mai apoi, să se întreprindă aç̧iuni pentru reducerea numărului acestor intervenţii medicale.

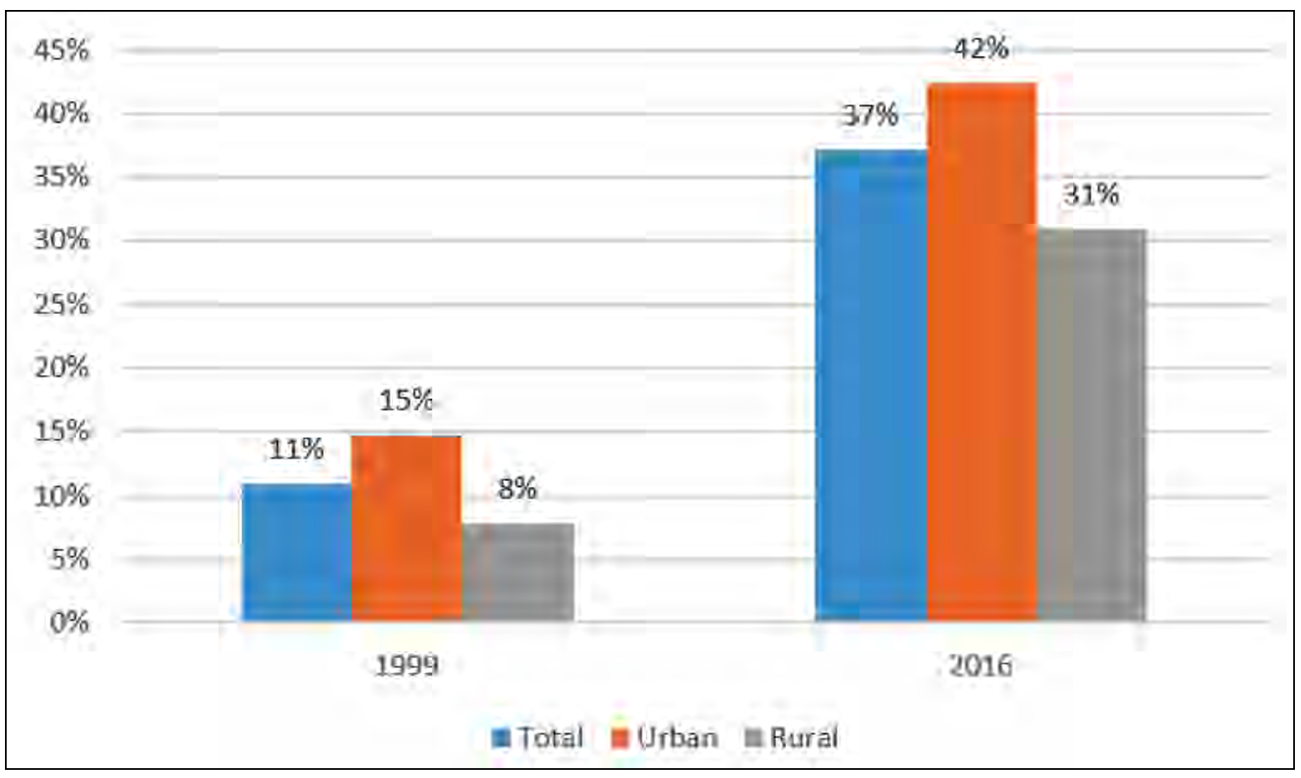

FIGURA 1. Diferenţa procentului de naşteri prin operaţie cezariană (2009-2016) 


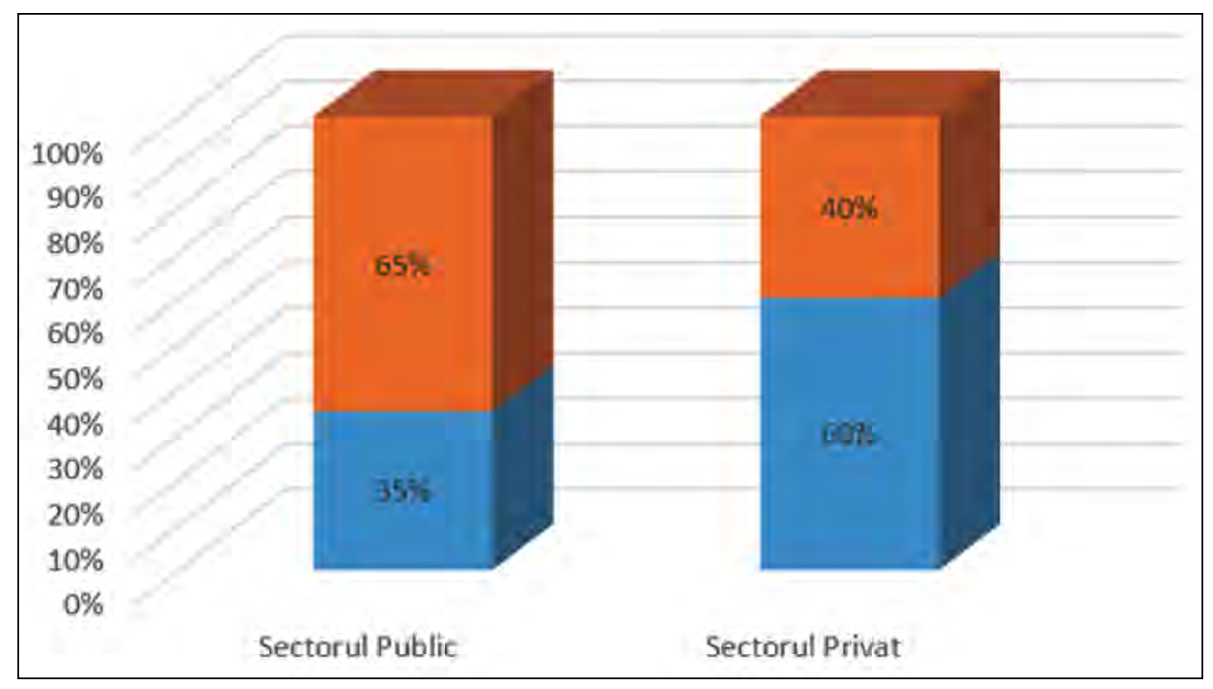

FIGURA 2. Tipul naşterii în funcţie de locul naşterii (instituţie medicală publică/privată)

\section{REZULTATE ŞI DISCUȚII}

În mod frecvent, operaţia cezariană este asociată cu vârsta, care, la rândul ei, este asociată cu probleme frecvente de contracţii uterine (reducerea contracţiilor spontane).

Un studiu realizat în Regatul Unit în perioada 1980-2005 pune în evidenţă faptul că 38\% dintre operaţiile cezariene ar fi putut fi evitate în cazul în care nu s-ar fi luat în considerare vârsta mamei [10].

În România, a existat o creştere semnificativă a procentului de operaţii cezariene pe o perioadă de 30-35 de ani, după care a avut loc o mică scădere (fig. 3).

Luând în considerare o mulţime de studii şi bazându-ne şi pe experienţa proprie, suntem de acord că vârsta pacientei poate reprezenta un risc la naştere, însă experienţa practică demonstrează că un procent semnificativ de paciente cu vârsta de peste 30 de ani au parte de naşteri pe cale vaginală în cele mai bune condiţii.

Există însă câteva indicaţii importante care recomandă o astfel de intervenţie. Printre acestea se numără bolile cardiovasculare, diabetul zaharat şi obezitatea (care este asociată cu o prevalenţă ridicată a naşterilor prin cezariană).

Dezvoltarea protocoalelor medicale pentru abordarea diverselor boli legate de sarcină, individualizarea abordării în funcţie de starea patologică a femeii, abordarea interdisciplinară şi cea de-a doua opinie pot reduce în mod semnificativ operaţia cezariană.

Distocia reprezintă o altă indicaţie majoră a operaţiei cezariene. Cazul distociei mecanice, în special, este considerată ca fiind cea mai comună cauză pentru naşterile prin operaţie cezariană (20\%-30\% dintre cazuri).

În România, specialiştii consideră că distocia este diagnosticul utilizat în mod abuziv pentru jus-

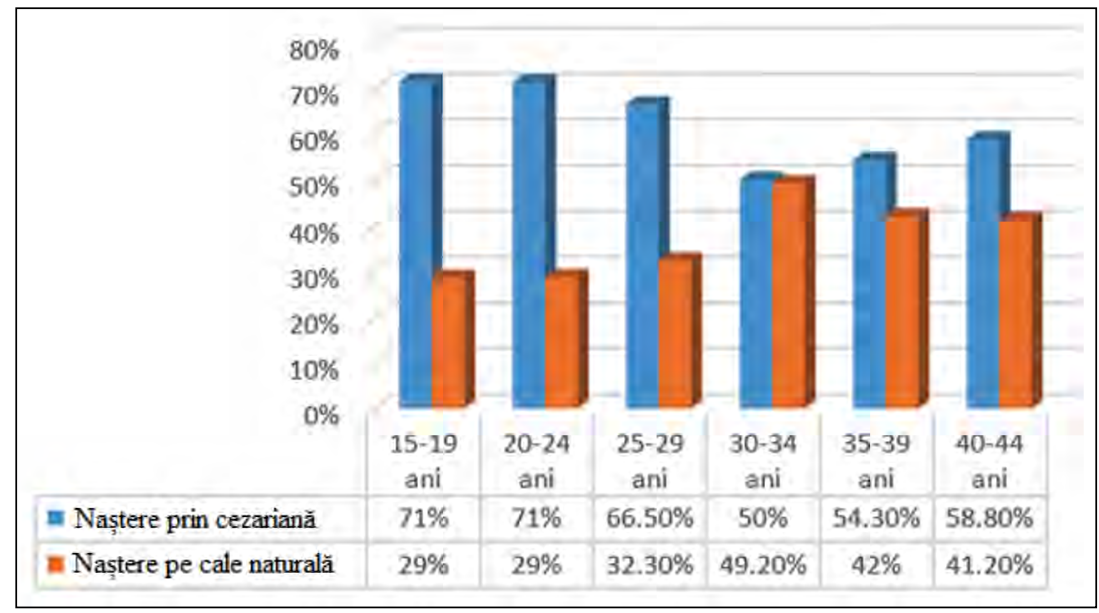

FIGURA 3. Naşterea prin cezariană şi pe cale naturală asociată cu vârsta 
tificarea operaţiei cezariene, în special în cazul cezarienelor la cerere.

Abordarea naşterii ar trebui realizată, de asemenea, pe baza riscurilor şi beneficiilor evaluării sănătăţii fetale. Este foarte bine cunoscut faptul că bolile asociate sarcinii precum cardiopatia, anemia, sarcina prelungită, placenta praevia sau ruptura uterină afectează prognosticul fetal. Trebuie, de asemenea, menţionat faptul că atât anestezia, cât şi operaţia în sine au un efect negativ asupra prognosticului fetal. Ar trebui, de asemenea, să luăm în considerare faptul că naşterea prin cezariană, inclusiv cea programată, predispune la creşterea prevalenţei de hipertensiune pulmonară în comparaţie cu naşterea pe cale naturală, risc ce scade invers proporţional cu vârsta gestaţională $[22,23]$.

Pe de altă parte, în naşterile normale, frecvenţa cardiacă anormală a fătului nu a putut fi pusă în evidenţă ulterior, fapt ce a dus ca specialiştii să considere că operaţia cezariană în aceste cazuri nu este necesară, iar naşterea s-ar putea realiza pe cale vaginală fără a afecta prognosticul fetal. De aceea, considerăm foarte utilă elaborarea unor noi standarde pentru interpretarea şi urmărirea ritmului cardiac al fătului, fapt ce poate conduce la scăderea inidicaţiilor operaţiei cezariene.

Istoricul naşterilor prin cezariană predispune pacientele în proporţie de $90 \%$ la efectuarea unei noi operaţii cezariene, astfel, creşterea incidenţei unei prime naşteri prin cezariană cauzează un trend similar în viitoarele posibile naşteri. $O$ alegere atentă a pacientelor ce au efectuat operaţia cezariană anterior poate face ca naşterea pe cale naturală să devină mai tolerabilă faţă de o nouă operaţie cezariană $[10,15]$. Se încurajează naşterea pe cale vaginală după operaţia cezariană deoarece rata de rupturi uterine este foarte scăzută (0,3-1\% dintre naşteri) [12]. Rata de succes a naşterilor pe cale naturală după naşterea prin cezariană, cuantificată de 2 studii recent efectuate, este de $73,4 \%-75,5 \%$, riscul unei rupturi uterine fiind între $0,7 \%$ şi $0,9 \%$. Naşterea pe cale naturală în aceste cazuri are multiple beneficii, printre care: 0 durată mai mică de spitalizare, hemoragii reduse şi mai puţine infecţii şi episoade tromboembolice.

O alegere atentă a echipamentelor tehnice adecvate şi a unui personal medical bine pregătit poate asigura o naştere pe cale naturală după alte naşteri realizate anterior prin operaţie cezariană. Procentul operaţiilor cezariene la cerere este cuprins între $4 \%$ şi $18 \%$ din totalul naşterilor. În Norvegia, un studiu estimează un procent de 7,6\% în perioada 1998-1999 [18] .

Dreptul ca o pacientă să aleagă modalitatea de naştere a făcut ca procentul de operaţii cezariene să crească la nivel mondial. Frica de durere, imprevizibilitatea, sentimentul de nesiguranţă şi singurătate şi luarea în calcul a altor păreri că o cezariană în trecut indică în mod automat o a doua cezariană sunt argumente care o pot determina pe o gravidă să aleagă opţiunea unei alte operaţii cezariene $[24,25]$.

În aceste situaţii, o echipă multidisciplinară de specialişti, incluzând obstetricieni, pediatri, psihologi, asistente, moaşe, poate furniza un ansamblu optim pentru o informare completă a gravidei, astfel încât aceasta să poată lua o decizie corectă. Gravida ar trebui sfătuită cu privire la faptul că naşterea pe cale naturală are mai multe beneficii, printre care o durată mai mică de spitalizare, hemoragii reduse şi mai puţine infecţii şi episoade tromboembolice $[15,19]$.

În operaţia cezariană, există riscul unor complicaţii materne, iar o pacientă ce a efectuat o astfel de intervenţie poate avea nevoie de un timp de recuperare mai mare. Pacienta ar trebui să fie informată de toate riscurile şi beneficiile unei operaţii cezariene şi ar trebui să fie implicată şi susţinută de către specialişti în alegerea unei decizii.

\section{CONCLUZII}

Pentru reducerea operaţiilor cezariene, este necesară organizarea de echipe medicale bine pregătite, formate din mai mulţi specialişti (obstetricieni, psihologi, pediatri, medici de familie, asistente, moaşe), care să prezinte în detaliu riscurile operaţiei cezariene şi care să poată asista pacientele în luarea unor decizii corecte. Este foarte important ca pacienta să ţină cont atât de toate riscurile şi beneficiile intervenţiilor, cât şi de o a doua opinie medicală.

Operaţia cezariană nu este o abordare obligatorie după prima cezariană, în cazul distociei sau în cazul scăderii ritmului cardiac fetal. 


\section{BIBLIOGRAFIE}

1. Ana Pilar Betrán, Jianfeng Ye, Anne-Beth Moller, Jun Zhang, A. Metin Gülmezoglu, Maria Regina Torloni : The Increasing Trend in Caesarean Section Rates: Global, Regional and National Estimates (1990-2014). https://www.ncbi.nlm.nih.gov/ pmc/articles/PMC4743929/

2. Fadhley, Salim (2014). Cesarean section photography. WikiJournal of Medicine. 1 (2). doi:10.15347/wjm/2014.006. Archived from the original on 6 October 2016.

3. Declercq E, Young R, Cabral H, Ecker J. Is a rising cesarean delivery rate inevitable? Trends in industrialized countries, 1987 to 2007. Birth 2011,38(2):99-104.

4. Lurie S, Raz N, Boaz M, Sadan O, Golan A. Comparison of maternal outcomes from primary cesarean section during the second compared with first stage of labor by indication for the operation. European journal of obstetrics, gynecology, and reproductive biology 2014, 182:43-47.

5. IOMC, CDC, USAID, UNFPA, Ministerul Sănătăţii, UNICEF Studiul sănătăţii reproducerii în România 1993 - Raport final.

6. Cabrol, I. Pons, J.C. Goffinet F. Traite d'obstetrique. Flammation Medicine - Sciences, 2003.

7. Stativa E, Nanu M, Stoicescu S, Nowak C. Evaluarea programelor nationale de sanatate - esantion reprezentativ pe tară in România (raport INSMC 2010).

8. Nanu D. Operația cezariană - seria Ghiduri clinice pentru obstetrică şi ginecologie. Ghid 2010, ISBN 978-973-668-278-0.

9. Evaluation du taux de cesarienne; comparaisons avec d'autre pays; Qu'en dit OMS 2010 www.cesarine.org/avant/ etat_des_lieux_php

10. American College Obstetrics and Gynecology 2010. Vaginal birth after caesarean section deliver (116) 450-63. https://www.ncbi.nlm.nih.gov/ pubmed/20664418

11. $H$ Ehrenberg. The influence of obesity and diabetes on the risk of caesarean delivery.
American Journal of Obstetrics and Gynecology 2004. 191(3) 969-74

12. Nanu D. Esenţialul în obstetrică. Editura Medicală Amaltea, 2015. ISBN 978-973162-143-3.

13. Haywood Brown L. Merck Manual, 2011. Physiology of pregnancy, 19th edition.

14. Koudstaal J. Obstetric outcome of twin pregnancies after in-vitro fertilization: A matched control study in four Dutch University hospitals. Human Reproduction 2000, 15, No. 4, pp. 935-940.

15. Nistorescu D, Stativa E, Clocotici O et al. Acompanierea naşterii. Ed. Alpha, 2011.

16. Smith GCS, Cordeaux Y, White IR, Pasupathy D, Missfelder-Lobos, $\mathrm{H}$ et al. The Effect of Delaying Childbirth on Primary Cesarean Section Rates. PLoS Med 2008, 5(7): e144. doi10.1371/journal.pmed 0050144.

17. Cunningham, Levano, Bloom, Hauth, Rouse, Spong Williams Obstetrics 23rd. MCGraw-Hill Company Inc., 2000.

18. John Yeh, Jean Wactawski-Wende, James A. Shelton, Jennifer Reschke. Temporal trends in the rates of trial of labor in low-risk pregnancies and their impact on the rates and success of vaginal birth after cesarean delivery. AJOG, January 2006 (194).

19. Cotzias C, Peterson-Brown S, Fisk N. Obstetricians say yes to maternal request for elective caesarean section: A survey of current opinion. European Journal of Obstetrics, Gynecology Reproductive Biology 2001. (97)pp 15-16.

20. Clark SL. Maternal death in 21 st century. Causes, prevention and relationship to caesarean delivery. American Journal Obstetrics Gynecology 2008. 199(1) pp. 36.

21. Subtil $D$, Vaast $P$. Maternal consequences of cesarean as related to vaginal delivery. Journal Gynecologie Obstetrique et Biologie de la Reproduction 2000, vol. 29, pp. 10.

22. Morrison JJ, Rennie JM, Milton PJ Neonatal respiratory morbidity and mode of delivery at term, influence of timing of elective cesarean section. British Journal Obstetrics - Gynecology 1995, 102(2) pp. 101-109.

23. Smith GC, Pell JP, Cameron AD, Dobbie R. Risk of perinatal death associated with labor after previous caesarean delivery in uncomplicated term pregnancy JAMA 2002. 18;288(11):1352.

24. National Institute of Health, State of the Science Conference Statement 2006 Caesarean Delivery on Maternal Request, Obstetrics - Gynecology 107(6).

25. Heimann S. La Cesarienne sur demande maternelle: Quelle est la vraie demande de la mère? Revue Francaise de Medicine Perinatale, 2001 http://www.cesarine.org/ avant/programmee/convenance

26. Hartmann KE, Andrews JC, Jerome RN, Lewis RM, Likis FE, McKoy JN, Surawicz TS, Walker SH. Strategies To Reduce Cesarean Birth in Low-Risk Women Comparative Effectiveness Review. Agency for Healthcare Research and Quality (US); 2012 Oct. Report No.: 12(13)-EHC128-EF.

27. Chaillet N, Dumont A. Evidence based strategies for reducing Cesarean section rates: A meta-analysis. Birth 2007, 34(1), pp. 53-64.

28. Ares De Campos D, Cruz J, Medeiros Borges C, Costa Santos C, Vicente L. Lowered national cesarean section rates after a concerted action. Acta Obstetricia Gynecologica Scandinavica 2015, 94(4), 391-398.

29. Caughey A, Cahill A. Safe prevention of the primary caesarean delivery. AGOC, 2014.

30. Banca Mondială, UNFPA, USAID, UNICEF 2004. Studiul sănătăţii reproducerii în România 2004, Raport sintetic. Ed. Alpha MDN, Buzău.

31. Ministerul Sănătăţii, INSMC 2016 Studiul sănătăţii reproducerii 2016, date nepublicate. 